\title{
Trends in Gender Differences in Self-Rated Health in Korea: Evidence from the Korean National Health and Nutrition Examination Survey, 2001-2012
}

\author{
Belinda L. Needham ${ }^{1}$, Soojung Kim ${ }^{2}$, Erica Concors ${ }^{1} \&$ Jeffrey J. Wing ${ }^{3}$ \\ ${ }^{1}$ Department of Epidemiology and Center for Social Epidemiology and Population Health, University of Michigan, \\ Ann Arbor, MI, USA \\ ${ }^{2}$ Department of Public Health Care and Management, Seoul National University, Seoul, Korea \\ ${ }^{3}$ Department of Public Health, Grand Valley State University, Allendale, MI, USA \\ Correspondence: Belinda L. Needham, Department of Epidemiology and Center for Social Epidemiology and \\ Population Health, University of Michigan, 1415 Washington Heights, 2649A SPH Tower, Ann Arbor, MI, USA. \\ Tel: 1-734-615-9228. E-mail: needhamb@umich.edu
}

Received: January 19, 2017 Accepted: February 22, 2017 Online Published: March 7, 2017

doi:10.5539/gjhs.v9n5p196 URL: https://doi.org/10.5539/gjhs.v9n5p196

\begin{abstract}
Despite rapid economic growth during the last half of the twentieth century, gender inequality has remained high in Korea. Using data from the 2001 Korean National Health and Nutrition Examination Survey (KNHANES), previous research found that gender differences in sociostructural and psychosocial factors contributed to a substantial female excess in poor self-rated health. To the extent that women's overall social status relative to men has improved over time in Korea, it is possible that the gender gap in perceived health has decreased. This study used repeated cross-sectional KNHANES data from 2001-2012 to examine temporal trends in gender differences in self-rated health. In age-adjusted models, we found no significant trend in the female excess of poor self-rated health among respondents aged 25-44 $(\mathrm{p}=0.685)$. In contrast, we found a statistically significant downward trend among those aged 45-64 ( $<<0.001)$. In fully adjusted models controlling for age and behavioral, sociostructural, and psychosocial covariates, we found a marginally significant upward trend $(\mathrm{p}=0.08)$ among younger respondents, while the downward trend among older respondents remained significant $(p<0.001)$. More work is needed to determine why gendered health disparities decreased among older adults in Korea but not among those aged 25-44.
\end{abstract}

Keywords: gender differences, self-rated health, temporal trends, Korea

\section{Introduction}

When the Korean War ended in 1953, South Korea was one of the poorest countries in the world. Since the mid-twentieth century, however, the nation has undergone rapid economic development. According to the International Monetary Fund, Korea (Note 1) was the $11^{\text {th }}$ richest country in the world in 2014, with an estimated gross domestic product equal to 1.4 trillion US dollars (IMF 2015). While economic growth tends to be accompanied by a reduction in gender inequality (Duflo 2012), previous research suggests that changes in the status of Korean women relative to men have lagged behind changes in the economy, resulting in a substantial gender gap in perceived health (Chun et al. 2008). In this paper, we review recent trends in educational, economic, and household labor inequality between women and men in Korea and use nationally representative data from the Korean National Health and Nutrition Examination Survey (KNHANES) to determine whether gender differences in poor self-rated health increased, decreased, or remained the same over a 12-year period from 2001 to 2012.

\subsection{Trends in Educational, Economic, and Household Labor Inequality}

Between 2001 and 2012, the percentage of Korean women with a college degree increased by $66 \%$, compared to an increase of $41 \%$ among men (Ministry of Education 2013). Despite substantial increases in women's educational attainment since the turn of the twenty-first century, the female labor force participation rate in Korea remained virtually unchanged from $47.7 \%$ in 2001 to $48.4 \%$ in 2012 (Statistics Korea 2015). Furthermore, traditional gender roles have continued to shape women's occupational opportunities and choices, resulting in significant differences in earnings. In 2013, the pay gap between Korean women and men was the highest of all 34 
member countries in the Organization for Economic Cooperation and Development (OECD 2013).

Gender inequality in the private sphere has also persisted at a very high level in Korea, even among dual-income couples (Oshio, Nozaki, and Kobayashi 2013). According to a 2005 report published by the Korean National Statistics Office, $88 \%$ of women reported doing almost all or all of the chores around the home (as cited in Chun et al. 2008). Data from the Korean Longitudinal Survey of Women and Families suggests that women continue to perform the vast majority of household tasks. In 2007, women reported spending an average of 263 minutes per day on household chores, compared to an average of 22 minutes per day reported by men. By 2012, women reported spending an average of 162 minutes per day on household tasks, while men reported spending an average of only 17 minutes per day on chores around the house (Joo et al. 2014).

\subsection{Social Status and Health Inequality}

Previous research using data from the 2001 KNHANES found that women in Korea were significantly more likely than men to report poor self-rated health, and the gender disparity was more pronounced among those aged 45-64 compared to those aged 25-44 (Chun et al. 2008). Differences in sociostructural factors, including education, occupational class, employment status, income, and marital status, explained $36 \%$ of the gender gap in perceived health among the younger participants and $61 \%$ of the gap among the older participants, while differences in psychosocial factors, including depressed affect, perceived stress, and fatigue, explained $35 \%$ of the gender gap in perceived health among the younger participants and $28 \%$ of the gap among the older participants (Chun et al. 2008). To the extent that women's social status relative to men has improved since 2001, we might expect to observe a decrease in the gender gap in perceived health over time. However, based on the evidence reviewed here regarding gender differences in educational, economic, and household labor inequality, it is unclear whether the overall status of women relative to men has improved in Korea in recent years. Gains in status due to increasing educational attainment may have been offset by income inequality and inequality in the division of household labor Moreover, any gains in status were likely limited to younger cohorts of women. Thus, we hypothesized that the gender gap in poor self-rated health remained the same from 2001 to 2012 among older participants (aged 45-65) but was attenuated slightly over time among younger participants (aged 25-44).

\section{Methods}

Data were from the Korean National Health and Nutrition Examination Survey (KNHANES), 2001, 2005, 2007-2009, and 2010-2012. Beginning in 2007, the survey moved to continuous data collection in three-year cycles. The samples for 2001, 2005, and each three-year cycle from 2007 to 2012 were based on a probability sample of the non-institutionalized Korean population. Household members within census tracts were selected using a stratified, multistage sampling design. Between 2001 and 2012, response rates ranged from $71.2 \%$ to $88.5 \%$. Written informed consent was obtained from all study participants, and the study protocol was approved by the Institutional Review Board of the Korean Center for Disease Control and Prevention (Ministry of Health and Welfare of Korea Korea Centers for Disease Control and Prevention 2014). The dataset used in the current study was completely de-identified and was, therefore, not subject to IRB approval at the University of Michigan, where all analyses were conducted. The combined analytic sample, which excluded participants with missing data on one or more variables included in the models, consisted of 36436 respondents (15967 men and 20469 women) aged 25-64 ( $\mathrm{n}=6280$ in 2001, $\mathrm{n}=5883$ in 2005, $\mathrm{n}=11894$ in 2007-2009, and $\mathrm{n}=12379$ in 2010-2012). The number of cases with missing data ranged from a low of 36 in the 2001 survey to a high of 435 in the 2007-2009 survey, and no item was missing more than $6 \%$ of cases in any survey year.

\subsection{Measures}

Self-rated health was assessed by asking respondents about their general health status. Responses included very good, good, fair, poor, or very poor. Consistent with previous research using the 2001 KNHANES data (Chun et al. 2008 ), we created a dichotomous measure of poor self-rated health ( $1=$ fair, poor, or very poor health; $0=$ very good or good health). (Note 2) Gender was coded 1 for female and 0 for male. Age was a continuous variable, measured in years. Behavioral covariates included smoking (dummy variables for never, current, and former) and drinking (dummy variables for never, current, and former). Sociostructural covariates included educational attainment (dummy variables for tertiary [college or higher], secondary [high school], and primary [middle school or less]), occupational class (dummy variables for non-manual [legislators, senior officers and managers, professionals, technicians and associate professionals, and office workers], manual [service and sales workers, skilled agricultural and related trades workers, plant/machine operators/assemblers, and unskilled labor], and economically inactive [unemployed and non-employed, including housewives and students]), employment status (dummy variables for full-time, part-time, self-employed, and economically inactive), tertiles of equivalized household income (total household income divided by the square root of the number of household members), and 
living arrangement (dummy variables for never married, married couple only, married living with others, and previously married). Psychosocial covariates included dichotomous measures of perceived stress (1=high/very high; $0=$ low/nearly none) and depressed affect $(1=$ one or more symptoms in the past two weeks; $0=$ no symptoms in the past two weeks).

\subsection{Plan of Analysis}

We used the direct method of standardization (Rothman, Greenland, and Lash 2008) to compare the prevalence of poor self-rated health for women and men. At each survey year (2001, 2005, 2007-2009, and 2010-2012), we multiplied the age-specific prevalence in the study population by the proportion of people in corresponding five-year age groups from the 2010 Korean Census and then summed the results to obtain the age-adjusted estimates. We calculated $95 \%$ confidence intervals for the age-adjusted rates assuming a Poisson distribution.

Next, we used Poisson regression with robust standard errors (Hilbe 1999) to estimate prevalence ratios (PR) for gender differences in poor self-rated health, adjusting for covariates. When an outcome is common (incidence greater than or equal to $10 \%$ ), it is preferable to estimate the PR rather than the odds ratio (Deddens and Petersen 2008, Behrens et al. 2004). We adjusted for covariates in steps, following prior work by Chun and colleagues (2008). The first model adjusted for age only. Model 2 adjusted for age and health risk behaviors (smoking and drinking) that are more common among Korean men than women and could, therefore, suppress the association between gender and poor self-rated health, underestimating the association. Model 3 adjusted for everything in Model 2, plus the sociostructural covariates (education, occupational class, employment, income, and living arrangement). Model 4 adjusted for everything in Model 2, plus the psychosocial covariates (perceived stress and depressed affect), which were hypothesized to reflect gender differences in aspects of social status, such as the division of household labor, that were not measured in KNHANES. Finally, Model 5 adjusted for all covariates, including age, potential behavioral suppressors, and potential sociostructural and psychosocial mediators. For each survey year, we ran models for the full sample and by age (25-44 years and 45-64 years). The AIC and BIC were used to assess model fit. In models pooled across survey years, we calculated linear time trends in the PR of poor self-rated health by examining the p-value for an interaction between gender and a variable for survey year (see Khang, Yun, and Lynch 2008). Analyses were conducted in STATA, version 12.0 (College Station, TX), using the recommended sample weights (pooled weights for 2007-2009 and 2010-2012).

\section{Results}

Among both women and men, the prevalence of poor self-rated health increased over time (Table 1). Among women, the prevalence increased from $51.2 \%$ in the 2001 survey to $67.7 \%$ in the $2010-2012$ survey; and among men, the prevalence increased from $44.2 \%$ to $62.9 \%$. (Note 3) As shown in Figure 1, the female excess in the prevalence of poor self-rated health remained fairly constant over time in the full sample, masking contrasting trends among younger and older respondents. Among those aged 45-64, the female excess in poor self-rated health declined substantially between the 2001 and 2010-2012 surveys. Among respondents aged 25-44, however, the gender difference increased between the 2001 and 2005 surveys and then appeared to level off. In the 2001 survey, the female excess in poor self-rated health was substantially higher among older respondents, but by the 2010-2012 survey, the gender gap was virtually the same for older and younger respondents.

Table 1 . The age-adjusted percentage ( $95 \%$ confidence interval) of respondents reporting poor self-rated health, by gender and KNHANES survey year

\begin{tabular}{llll}
\hline Survey Year & Sample Size & Female & Male \\
\hline 2001 & 6280 & $51.2(48.8,53.6)$ & $44.2(42.0,46.4)$ \\
2005 & 5883 & $60.2(58.2,62.3)$ & $52.5(50.4,54.6)$ \\
$2007-2009$ & 11894 & $62.7(61.0,64.3)$ & $55.5(53.9,57.2)$ \\
$2010-2012$ & 12379 & $67.7(66.3,69.2)$ & $62.9(61.3,64.5)$ \\
\hline
\end{tabular}




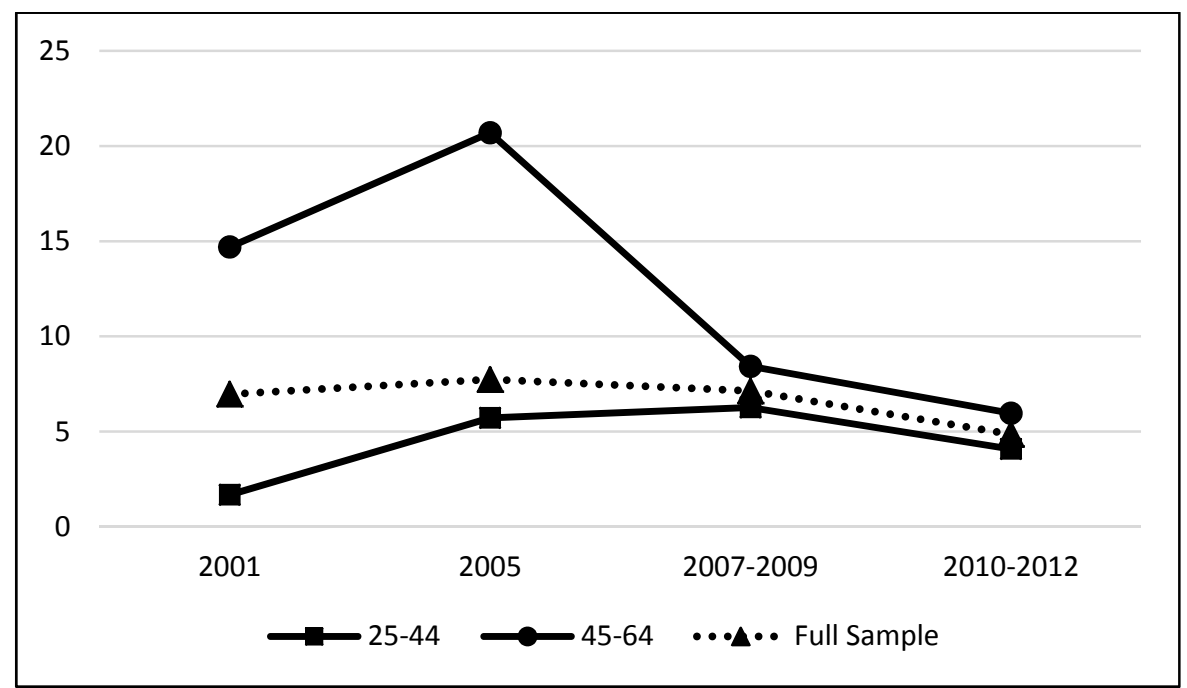

Figure 1. Female excess in the age-adjusted prevalence of poor self-rated health, by KNHANES survey year

In all years, there were significant gender differences in each of the behavioral, sociostructural, and psychosocial covariates examined (Table 2). Between the 2001 and 2010-2012 surveys, the percentage of women who reported current smoking increased from $3.8 \%$ to $5.6 \%$, while the percentage of men who reported current smoking decreased from $64.3 \%$ to $46.5 \%$. In contrast to the results for smoking, the percentage of respondents who reported current drinking increased over time for both women and men (from $62.8 \%$ to $69.3 \%$ among women and from $85.1 \%$ to $88.5 \%$ among men). Along with an increase over time in the percentage of women and men who reported college completion, the gender gap in tertiary education was reduced by approximately $40 \%$ between the 2001 and 2010-2012 surveys. Despite substantial gains in educational attainment, the percentage of women who reported being economically inactive remained high throughout the study period ( $46.5 \%$ of women vs. $12.1 \%$ of men in the most recent survey), and men were consistently more likely than women to be in the highest tertile of equivalized household income $(33.2 \%$ of women vs. $35.5 \%$ of men in the most recent survey). The percentage of never-married women and men remained fairly constant over time, with men significantly more likely than women to report being single in all survey years ( $9.5 \%$ of women vs. $14.6 \%$ of men in the most recent survey). In 2001 , women were more likely than men to report high or very high perceived stress $(66.3 \%$ of women vs. $62.9 \%$ of men), but the gender gap reversed by 2010-2012 (71.8\% of women vs. $73.5 \%$ of men). Between the 2001 and 2005 surveys, there was a substantial increase in the percentage of women and men who reported at least one symptom of depression in the past two weeks, with a leveling off in the prevalence of depressed affect between the 2005 and 2010-2012 surveys. The female excess in depressed affect persisted across time ( $15.9 \%$ of women vs. $8.6 \%$ of men the most recent survey). Finally, while there were no significant gender differences in age, the percentage of women and men in the younger age category declined substantially between the 2001 and 2010-2012 surveys, consistent with prior reports of a rapidly aging Korean population (Lee and Mason 2011).

Table 2. Unweighted percentages for study covariates, by gender and KNHANES survey year

\begin{tabular}{|c|c|c|c|c|c|c|c|c|c|c|c|c|}
\hline & \multicolumn{3}{|l|}{2001} & \multicolumn{3}{|l|}{2005} & \multicolumn{2}{|l|}{ 2007-2009 } & \multicolumn{3}{|c|}{$2010-2012$} & \multirow[b]{2}{*}{ p-value } \\
\hline & $\begin{array}{l}\text { Female } \\
(n=3 \\
329)\end{array}$ & $\begin{array}{l}\text { Male } \\
(\mathrm{n}=2 \\
951)\end{array}$ & p-value & $\begin{array}{l}\text { Female } \\
(\mathrm{n}=3 \\
163)\end{array}$ & $\begin{array}{l}\text { Male } \\
(\mathrm{n}=2 \\
720)\end{array}$ & p-value & $\begin{array}{l}\text { Female } \\
(n=6 \\
814)\end{array}$ & $\begin{array}{l}\text { Male } \\
(\mathrm{n}=5 \\
080)\end{array}$ & p-value & $\begin{array}{l}\text { Female } \\
(n=7 \\
163)\end{array}$ & $\begin{array}{l}\text { Male } \\
(\mathrm{n}=5 \\
216)\end{array}$ & \\
\hline \multicolumn{13}{|l|}{ Age } \\
\hline $25-44$ & 62.2 & 62.2 & & 57.3 & 55.5 & & 52.5 & 51.0 & & 48.5 & 47.7 & \\
\hline $45-64$ & 37.9 & 37.9 & & 42.7 & 44.5 & & 47.5 & 49.0 & & 51.5 & 52.3 & \\
\hline \multicolumn{13}{|l|}{ Smoking } \\
\hline Never & 95.3 & 19.7 & $* * *$ & 91.4 & 14.9 & $* * *$ & 88.8 & 17.3 & $* * *$ & 88.9 & 17.4 & $* * *$ \\
\hline Current & 3.8 & 64.3 & & 5.2 & 54.9 & & 5.7 & 48.9 & & 5.6 & 46.5 & \\
\hline Former & 1.0 & 16.0 & & 3.4 & 30.2 & & 5.5 & 33.8 & & 5.5 & 36.1 & \\
\hline
\end{tabular}




\begin{tabular}{|c|c|c|c|c|c|c|c|c|c|c|c|c|}
\hline \multicolumn{13}{|l|}{ Drinking } \\
\hline Never & 35.7 & 11.4 & $* * *$ & 10.9 & 6.3 & $* * *$ & 15.0 & 4.1 & $* * *$ & 14.0 & 3.2 & $* * *$ \\
\hline Current & 62.8 & 85.1 & & 72.5 & 88.5 & & 68.5 & 87.5 & & 69.3 & 88.5 & \\
\hline Former & 1.5 & 3.5 & & 16.6 & 5.2 & & 16.6 & 8.4 & & 16.7 & 8.3 & \\
\hline \multicolumn{13}{|l|}{ Education } \\
\hline Tertiary & 23.4 & 39.0 & $* * *$ & 25.2 & 37.1 & $* * *$ & 28.0 & 37.9 & $* * *$ & 34.4 & 44.1 & $* * *$ \\
\hline Secondary & 41.8 & 39.0 & & 41.4 & 40.9 & & 38.7 & 38.0 & & 36.6 & 35.8 & \\
\hline Primary & 34.8 & 22.0 & & 33.4 & 22.0 & & 33.3 & 24.1 & & 29.1 & 20.1 & \\
\hline \multicolumn{13}{|l|}{ Occupation } \\
\hline Non-manual & 11.8 & 29.9 & $* * *$ & 16.0 & 29.3 & $* * *$ & 17.3 & 31.1 & $* * *$ & 20.1 & 36.2 & $* * *$ \\
\hline Manual & 35.7 & 57.8 & & 38.3 & 57.1 & & 35.1 & 55.0 & & 33.5 & 51.7 & \\
\hline $\begin{array}{l}\text { Economically } \\
\text { inactive }\end{array}$ & 52.5 & 12.3 & & 45.7 & 13.6 & & 47.6 & 13.9 & & 46.5 & 12.1 & \\
\hline \multicolumn{13}{|l|}{$\begin{array}{l}\text { Employment } \\
\text { status }\end{array}$} \\
\hline Full-time & 18.6 & 45.2 & $* * *$ & 19.2 & 43.1 & $* * *$ & 24.3 & 47.6 & $* * *$ & 25.3 & 51.5 & $* * *$ \\
\hline Part-time & 8.7 & 8.1 & & 15.3 & 13.7 & & 7.4 & 3.8 & & 8.5 & 2.4 & \\
\hline Self-employed & 9.2 & 33.9 & & 10.2 & 29.8 & & 14.1 & 33.1 & & 12.0 & 31.9 & \\
\hline $\begin{array}{l}\text { Economically } \\
\text { inactive }\end{array}$ & 63.5 & 12.8 & & 55.3 & 13.4 & & 54.2 & 15.4 & & 54.2 & 14.2 & \\
\hline \multicolumn{13}{|l|}{$\begin{array}{l}\text { Equivalized } \\
\text { household } \\
\text { income }\end{array}$} \\
\hline Tertile 1 (high) & 34.7 & 36.9 & $*$ & 36.7 & 39.7 & $* *$ & 32.8 & 35.5 & $* * *$ & 33.2 & 35.5 & $* * *$ \\
\hline $\begin{array}{ll}\text { Tertile } & 2 \\
\text { (middle) } & \end{array}$ & 29.6 & 30.8 & & 28.5 & 29.3 & & 35.2 & 35.7 & & 34.0 & 35.4 & \\
\hline Tertile 3 (low) & 35.7 & 32.3 & & 34.8 & 31.0 & & 32.0 & 28.8 & & 32.8 & 29.1 & \\
\hline \multicolumn{13}{|l|}{$\begin{array}{l}\text { Living } \\
\text { arrangement }\end{array}$} \\
\hline Never married & 8.1 & 15.6 & $* * *$ & 9.9 & 16.5 & $* * *$ & 7.5 & 14.7 & $* * *$ & 9.5 & 14.6 & $* * *$ \\
\hline $\begin{array}{l}\text { Married, } \\
\text { couple only }\end{array}$ & 12.2 & 10.6 & & 15.6 & 13.6 & & 14.7 & 13.3 & & 16.8 & 15.2 & \\
\hline $\begin{array}{l}\text { Married, living } \\
\text { with others }\end{array}$ & 69.6 & 70.7 & & 62.2 & 63.8 & & 66.0 & 67.0 & & 65.1 & 66.6 & \\
\hline $\begin{array}{l}\text { Previously } \\
\text { married }\end{array}$ & 10.1 & 3.2 & & 12.4 & 6.0 & & 11.8 & 5.1 & & 8.7 & 3.6 & \\
\hline \multicolumn{13}{|l|}{$\begin{array}{l}\text { Perceived } \\
\text { stress }\end{array}$} \\
\hline High/very high & 66.3 & 62.9 & $* *$ & 65.5 & 62.2 & $* *$ & 69.7 & 71.8 & $*$ & 71.8 & 73.5 & $*$ \\
\hline $\begin{array}{l}\text { Low/nearly } \\
\text { none }\end{array}$ & 33.7 & 37.1 & & 34.5 & 37.8 & & 30.3 & 28.2 & & 28.2 & 26.5 & \\
\hline \multicolumn{13}{|l|}{$\begin{array}{l}\text { Depressed } \\
\text { affect }\end{array}$} \\
\hline $\begin{array}{l}>=1 \text { symptom } \\
\text { in past } 2 \text { weeks }\end{array}$ & 0.9 & 0.2 & $* * *$ & 17.3 & 11.3 & $* * *$ & 17.3 & 9.9 & $* * *$ & 15.9 & 8.6 & $* * *$ \\
\hline $\begin{array}{l}0 \text { symptoms in } \\
\text { past } 2 \text { weeks }\end{array}$ & 99.1 & 99.8 & & 82.7 & 88.8 & & 82.7 & 90.1 & & 84.2 & 91.4 & \\
\hline
\end{tabular}

Note. P-values for gender differences calculated by $\chi^{2}$ tests. ${ }^{*} \mathrm{p}<0.05,{ }^{*} \mathrm{p}<0.01,{ }^{* * *} \mathrm{p}<0.001$ 
In age-adjusted models for the full sample, women were more likely than men to report poor health in all survey years (Table 3, Model 1). The PR decreased from 1.16 (95\% CI: 1.09, 1.22) in 2001 (Note 4) to 1.08 (95\% CI: 1.04, 1.11 ) in 2010-2012, and the temporal trend was statistically significant $(\mathrm{p}=0.005)$. Prevalence ratios increased after adjustment for current smoking and current drinking in Model 2, but a similar downward trend was observed $(\mathrm{p}<0.001)$. In Model 3, further adjustment for sociostructural covariates, including education, occupation, employment status, household income, and living arrangement, attenuated associations observed in Model 2, whereas further adjustment for psychosocial covariates, including perceived stress and depressed affect, did not (see Model 4). Prevalence ratios in the fully adjusted models (Model 5), which controlled for age and behavioral, sociostructural, and psychosocial covariates, were similar to those in Model 3, suggesting that perceived stress and depressed affect were not major contributors to gender differences in self-rated health. The AIC and BIC were lowest for the fully adjusted model (results not shown), which indicates that Model 5 provided the best fit for the data. The temporal trend was significant $(\mathrm{p}<0.001)$ in the fully adjusted model, but a comparison of the prevalence ratios from year-to-year suggested that the direction of the trend was unclear. The PR increased from 1.12 (95\% CI: $1.02,1.23)$ in 2001 to 1.15 (95\% CI: 1.06, 1.25) in 2005, then decreased to 1.11 (95\% CI: 1.05, 1.17) in 2007-2009 and increased to 1.14 (95\% CI: $1.08,1.19)$ in 2010-2012. PR differences between survey years indicated that the only significant difference between adjacent surveys was the increase that occurred between the 2007-2009 and 2010-2012 surveys $(\mathrm{p}=0.026)$.

Table 3. Temporal trends in the prevalence ratio ( $95 \%$ confidence intervals) for gender differences (female $=1)$ in less than good self-rated health, KNHANES 2001, 2005, 2007-2009, and 2010-2012

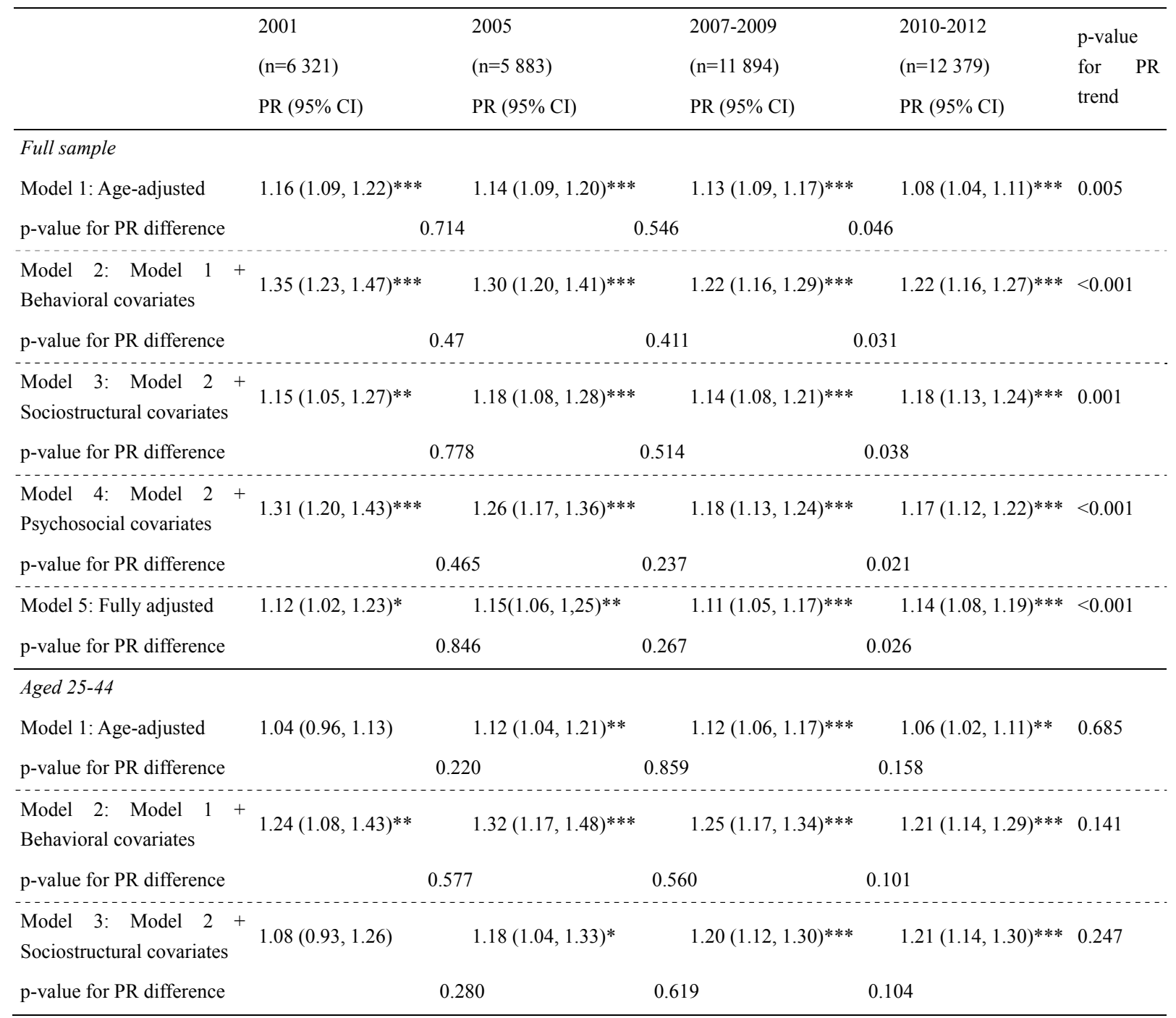




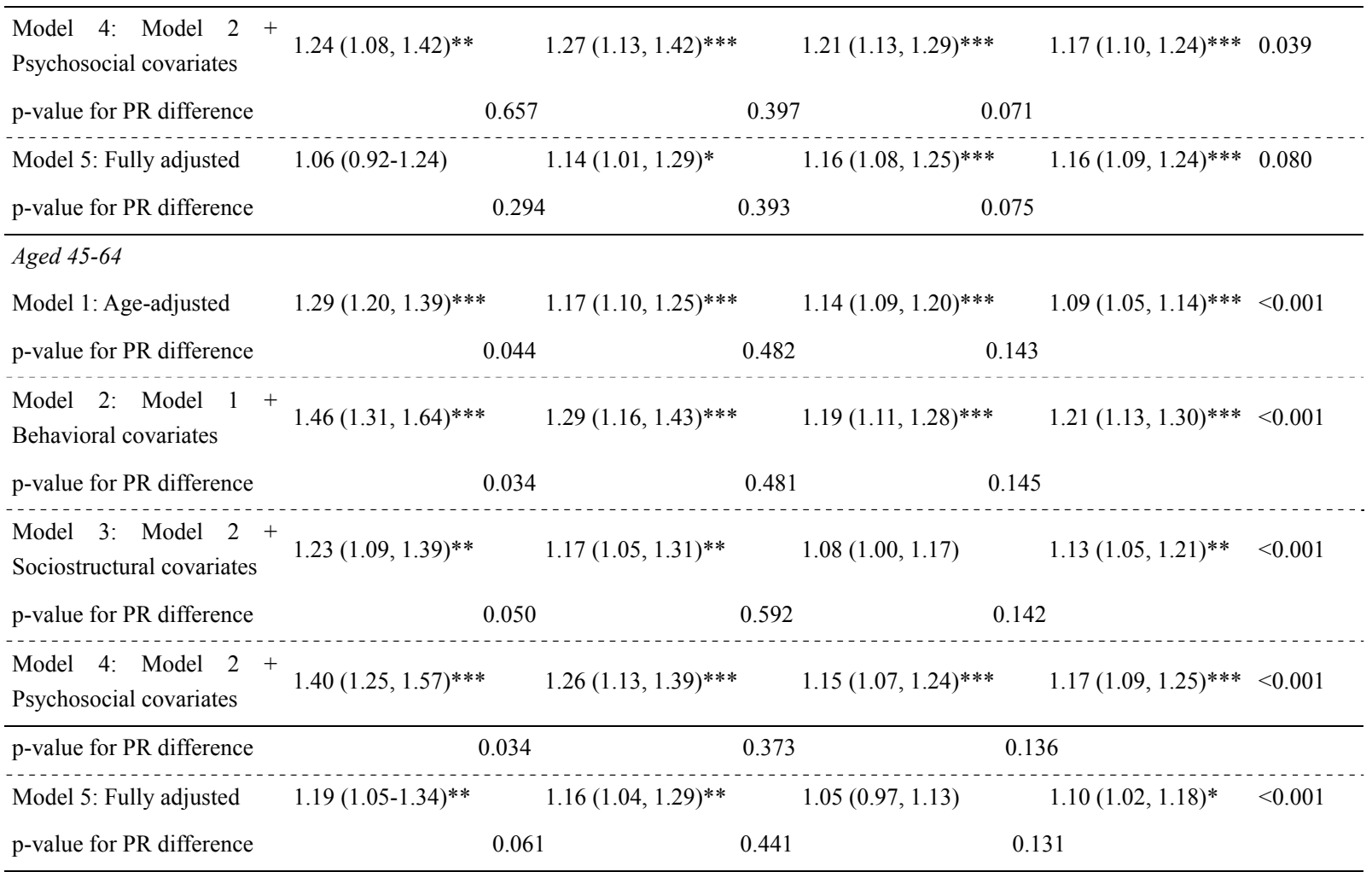

Note. $\mathrm{PR}=$ prevalence ratio; $\mathrm{CI}=$ confidence interval. ${ }^{*} \mathrm{p}<0.05,{ }^{* *} \mathrm{p}<0.01,{ }^{* * *} \mathrm{p}<0.001$

Contrasting temporal trends emerged in age-stratified models. In the fully adjusted models (Model 5), there was a marginally significant upward trend $(\mathrm{p}=0.08)$ in the female PR of poor self-rated health among respondents aged 25-44 ( $\mathrm{PR}=1.06,95 \%$ CI: $0.92,1.24$ in 2001 and $\mathrm{PR}=1.16,95 \%$ CI: $1.09,1.24$ in 2010-2012) and a statistically significant downward trend $(\mathrm{p}<0.001)$ among respondents aged 45-64 (PR=1.19, 95\% CI: 1.05, 1.34 in 2001 and $\mathrm{PR}=1.10,95 \%$ CI: $1.02,1.18$ in 2010-2012). This suggests that relative health inequality in Korea increased for younger women and men between 2001 and 2012, while it decreased for older women and men.

\section{Discussion}

Since the mid-twentieth century, South Korea has experienced remarkable economic growth, becoming one of the richest countries in the world. Although prior work suggests that economic growth is associated with a reduction in gender inequality (Duflo 2012), scholars have noted that the status of Korean women relative to men has remained low, resulting in a substantial gender gap in self-rated health (Chun et al. 2008). In fact, Korea ranked 117 out of 142 countries in the World Economic Forum's 2014 Global Gender Gap Report, ranking just below Qatar and just above Nigeria (World Economic Forum 2014). Despite the relatively low status of women in Korean society, gender-based disparities in economic participation, educational attainment, and political empowerment have decreased somewhat in Korea since the first Global Gender Gap Report was published in 2006 (World Economic Forum 2014). To the extent that women's overall social status relative to men has improved over time in Korea, it is possible that the gender gap in perceived health has decreased. Using repeated cross-sectional data from the Korean National Health and Nutrition Examination Survey (KNHANES), we found that the female excess in poor self-rated health increased slightly between 2001 and 2012 among younger respondents but decreased over time among older respondents. Results were contrary to hypotheses regarding age patterns and demonstrate a convergence in the gender gap in self-rated health between older and younger age groups in Korea.

The current study built on previous cross-sectional research that examined the gender gap in perceived health in Korea. Using data from the 2001 KNHANES survey, Chun et al. (2008) reported a significant female excess in poor self-rated health, with a larger disparity among respondents aged 45-64 compared to those aged 25-44. In both age groups, associations were attenuated after adjusting for sociostructural and psychosocial factors, suggesting that decreases in gender inequality could potentially lead to decreases in gender-based health disparities. To our knowledge, only one other study has examined time trends in gendered health disparities in Korea. Using data from six Korean Social Statistics Surveys collected between 1992 and 2010, Chun et al. (2012) found that the 
gender gap in poor self-rated health decreased, with evidence of a sharper decline in the disparity among those aged 25-44 compared to those aged 45-64. Although the Chun et al. (2012) study and the current study used similar methods to examine nationally representative data collected over a similar time frame, previous research has shown that trends in self-rated health varied markedly across national surveys in the US, with greater discrepancies found among young respondents (Salomon et al. 2009). This may explain why our results for young adults contrast with those reported by Chun et al. (2012), though it should also be noted that the two studies dichotomized measures of self-reported health differently - fair health combined with poor or very poor health in the current study (to be consistent with prior work in KNHANES) vs. fair health combined with good or very good health in the Chun et al. (2012) study. While more objective measures of health status, such as self-reported chronic conditions, have shown higher concordance across studies than measures of self-rated health (Salomon et al. 2009), KNHANES does not include comparable objective measures of health status in all survey years. Thus, we chose to focus on gender differences in perceived health.

\subsection{Strengths, Limitations, and Directions for Future Research}

Key strengths of this analysis include the use of nationally representative data, which enhanced generalizability; the use of time-series data, which facilitated an examination of temporal trends in the gender gap in perceived health; and the availability of data on hypothesized behavioral suppressors and sociostructural and psychosocial mediators of gender differences in health. Failure to adjust for potential behavioral suppressors, such as smoking, could lead to an underestimation of the female excess in poor health. Furthermore, adjustment for potential sociostructural and psychosocial mediators could help identify mechanisms underlying gender differences in perceived health, although it should be noted that the repeated cross-sectional design did not permit the assessment of temporal order between self-rated health and the hypothesized sociostructural, psychosocial, and behavioral mediators. As shown in Table 3, the prevalence ratios for poor self-rated health increased in the full sample and in both age groups when behavioral covariates were added to the age-adjusted model and then decreased when sociostructural and psychosocial covariates were added. With few exceptions, the coefficient for gender remained significant in the fully adjusted models, indicating that the female excess in poor health was not fully explained by gender differences in education, occupation, employment status, household income, living arrangement, perceived stress, and/or depressed affect in any survey year. Among respondents aged 45-64, a significant downward trend in the gender gap in self-rated health was evident in all models, suggestive of narrowing inequality in behavioral, sociostructural, and psychosocial factors. In contrast, among respondents aged 25-44, a marginally significant upward temporal trend in the gender difference in perceived health was only observed in the fully adjusted model. The results of Models 3 and 4 indicated the presence of countervailing trends after adjustment for sociostructural covariates (non-significant upward trend) and psychosocial covariates (significant downward trend). This suggests widening inequality in sociostructural factors coupled with narrowing inequality in psychosocial factors among younger respondents. Future research should examine these trends in greater detail and identify other factors, such as the division of household labor (data not available in KNHANES), that may contribute to gender differences in perceived health.

Although the purpose of this study was to examine recent time trends in the gender gap in perceived health, a potential limitation of health disparities research is the focus on relative health inequality rather than absolute levels of health and well-being in the subpopulations being compared. For example, the size of the gender gap in poor self-rated health would be exactly the same whether $20 \%$ of women and $10 \%$ of men reported poor health or $80 \%$ of women and $70 \%$ of men reported poor health. Furthermore, temporal trends in health disparities do not tell us whether absolute levels of health improved or declined over time. For example, disparities in poor health could have decreased whether absolute levels of perceived health increased or decreased in the population overall, and a decrease in disparities could have been due to improvements in the health of the disparity group coupled with no change in the comparison group or some other combination of factors resulting in a decrease in the difference between groups, such as a decline in the health of the disparity group coupled with an even greater decline in the health of the comparison group. In this study, we found that the percentage of respondents who reported poor health increased over time for women and men in both age groups. The gender gap in perceived health increased slightly among young adults because the percentage of respondents aged 25-44 who reported poor health increased more for women than men, while the gender gap decreased among older adults because the percentage of respondents aged 45-64 who reported poor health increased less for women than men. Future research should examine reasons for the apparent decline in self-rated health among the working-age population in Korea, including the possible role of financial and psychosocial factors associated with a slow-down in the economy and changes in the population age structure.

In order to be consistent with prior research (Chun et al. 2012, Chun et al. 2008), we compared temporal trends in 
the gender gap in perceived health for respondents aged 25-44 and 45-64. This provided a rough approximation of differences between younger and older birth cohorts. However, because KNHANES used a repeated cross-sectional design, some respondents in the older "cohort" during the 2005 survey were born in the same year as those in the younger "cohort" during the 2001 survey. To more closely approximate birth cohorts, future studies using the KNHANES data could compare time trends for respondents who were aged 25-44 and 45-64 at the baseline survey in 2001. For the 2010 data, this would mean comparing time trends for respondents who were aged 34-43 and 54-73 at the time of the survey. Finally, future research should consider using methods - such as those utilized by Beck et al. (2014) to examine black-white health disparities in the US - that simultaneously consider age, period, and cohort effects on temporal trends in the gender gap in self-rated health.

\subsection{Conclusions}

Using nationally representative data collected between 2001 and 2012, we observed contrasting temporal trends in gender-based disparities in perceived health among younger and older Korean adults. In fully adjusted models, we found that disparities narrowed over time among those aged 45-64, while the female excess in poor self-rated health increased among those aged 25-44. The trend among young adults was surprising given evidence that the status of Korean women relative to men has improved somewhat in recent years. More work is needed to understand the mechanisms underlying the age-specific patterns we observed. Furthermore, additional research is needed to identify explanations for the decline in perceived health that were found for all age-sex groups in the KNHANES data. To achieve the greatest public health impact, efforts to reduce health disparities should also aim to improve health for all groups in the population.

\section{Competing Interests Statement}

The authors declare that there is no conflict of interests regarding the publication of this paper.

\section{References}

Beck, A. N., Finch, B. K., Lin, S. F., Hummer, R. A., \& Masters, R. K. (2014). Racial disparities in self-rated health: Trends, explanatory factors, and the changing role of socio-demographics. Social Science \& Medicine, 104, 163-177. https://doi.org/10.1016/j.socscimed.2013.11.021

Behrens, T., Taeger, D., Wellmann, J., \& Keil, U. (2004). Different methods to calculate effect estimates in cross-sectional studies - A comparison between prevalence odds ratio and prevalence ratio. Methods of Information in Medicine, 43 (5), 505-509.

Chun, H., Cho, S. I., Khang, Y. H., Kang, M., \& Kim, I. H. (2012). Trends in gender-based health inequality in a transitional society: A historical analysis of South Korea. J Prev Med Public Health, 45(2), 113-21. https://doi.org/10.3961/jpmph.2012.45.2.113

Chun, H., Khang, Y. H., Kim, I. H., \& Cho. S. I. (2008). Explaining gender differences in ill-health in South Korea: the roles of socio-structural, psychosocial, and behavioral factors. Soc Sci Med, 67(6), 988-1001. https://doi.org/10.1016/j.socscimed.2008.05.034

Deddens, J. A., \& Petersen, M. R. (2008). Approaches for estimating prevalence ratios. Occupational and Environmental Medicine, 65(7), 501-506. https://doi.org/10.1136/oem.2007.034777

Duflo, E. (2012). Women Empowerment and Economic Development. Journal of Economic Literature, 50(4), 1051-1079. https://doi.org/10.1257/jel.50.4.1051.

Hilbe, J. (1999). Robust variance estimators for MLE Poisson and negative binomial regression. Stata Technical Bulletin. 8(45), 26-28.

IMF. (2015). April 2015 World Economic Outlook Database. International Monetary Fund.

Joo, J.-S., Moon, Y.-K., Kim, Y.-T., Lim, Y.-G., Son, Ch.-K., Cho, E.-J., \& Kang, E.-S. (2014). Korean Longitudinal Survey of Women \& Families: the 2014 Annual Report Korean Women's Development Institute.

Khang, Y. H., S. C. Yun, and J. W. Lynch. 2008. Monitoring trends in socioeconomic health inequalities: it matters how you measure. Bmc Public Health, 8, 1-6. https://doi.org/10.1186/1471-2458-8-66

Lee, Ronald Demos, and Andrew Mason. 2011. Population Aging and the Generational Economy: A Global Perspective Northampton. MA: Edward Elgar Publishing, Inc. https://doi.org/10.4337/9780857930583

Ministry of Education. 2013. Statistical Yearbook of Education. Ministry of Education and Korean Education Development Institute.

Ministry of Health and Welfare of Korea Korea Centers for Disease Control and Prevention. 2014. 2013 Korea 
Health Statistics. Seoul: Ministry of Health and Welfare of Korea.

OECD. 2013. Gender wage gap.

Oshio, T., Kayo, N., \& Miki, K. (2013). Division of household labor and marital satisfaction in China, Japan, and Korea. Journal of Family and Economic Issues, 34, 211-223. https://doi.org/10.1007/s10834-012-9321-4

Rothman, K. J., Sander, G., \& Timothy, L. L. (2008). Modern Epidemiology (3rd ed.). New York: Lippincott Williams \& Williams.

Salomon, J. A., Nordhagen, S., Oza, S., \& Murray, C. J. (2009). Are Americans feeling less healthy? The puzzle of trends in self-rated health. Am J Epidemiol, 170(3), 343-51. https://doi.org/10.1093/aje/kwp144

Statistics Korea. 2015. Korean Statistical Information Service Database.

World Economic Forum. 2014. The Global Gender Gap Report.

\section{Notes}

Note 1. In this paper, Korea refers to the Republic of Korea, commonly referred to as South Korea.

Note 2. Two self-rated health questions were available in the 2001 KNHANES. The first asked respondents to rate their usual health, while the second asked respondents to rate their health compared to others of the same age. The second question, which was used in the Chun et al. (2008) study, was discontinued after the 2001 survey. To ensure comparability of results across survey years, we used the first question in our analyses.

Note 3. Note that the numbers in Table 1 for the 2001 survey differ from those reported by Chun et al. (2008) due to (1) the use of a slightly different measure of self-rated health, as described above, (2) the use of different exclusion criteria for the analytic samples, and (3) the use of different standard populations.

Note 4. Note that the prevalence ratios in Table 3 for the 2001 survey differ from the odds ratios reported by Chun et al. (2008) due to (1) the use of a slightly different measure of self-rated health, as described above, (2) the use of different exclusion criteria for the analytic samples, and (3) the use of prevalence ratios rather than odds ratios.

\section{Copyrights}

Copyright for this article is retained by the author(s), with first publication rights granted to the journal.

This is an open-access article distributed under the terms and conditions of the Creative Commons Attribution license (http://creativecommons.org/licenses/by/4.0/). 